\title{
Menopause Symptoms' Severity Inventory (MSSI-38): assessing the frequency and intensity of symptoms
}

\author{
F. Pimenta, I. Leal, J. Maroco and C. Ramos \\ Psychology and Health Research Unit; ISPA - Instituto Universitário, Lisbon, Portugal \\ Key words: MENOPAUSE, SYMPTOM SEVERITY, INVENTORY,VALIDATION, PERIMENOPAUSE, POSTMENOPAUSE
}

\begin{abstract}
Objectives Menopausal instruments usually assess the frequency or intensity of symptoms. The present study develops and validates an inventory to assess the severity of menopausal symptoms through the measurement of their frequency and intensity, and explores the differences between women with different menopausal status.

Methods A community sample of 992 Portuguese women in pre-, peri- and postmenopause completed the proposed inventory with 47 items. Factor exploratory and confirmatory analyses, and comparative statistics for paired and independent samples, were applied using PASW Statistics v.19 and AMOS v.18 software.

Results The final structure with 38 items organized in 12 factors showed overall good psychometric properties (in terms of factor analysis, convergent, discriminant and criterion validity, as well as regarding reliability, sensitivity, and measure invariance in two different and independent samples). The Wilcoxon test confirmed significant differences between frequency and intensity of symptoms. Moreover, peri- and postmenopausal women in this community sample presented low symptom severity (ranging from 0.4 to 1.4 in a scale from 0 to 4 ). Although postmenopausal participants presented higher levels (when compared with their perimenopausal counterparts), the two groups only diverged significantly in some physical symptoms (namely, aches and pain, vasomotor symptoms, numbness, skin and facial hair changes, urinary and sexual symptoms).

Conclusion This research emphasizes that severity measurement of symptoms should account for both frequency and intensity. Moreover, it contributes a fully validated 12-dimenson inventory for menopausal symptoms, the Menopause Symptoms' Severity Inventory-38. Regarding differences between peri- and postmenopausal women, the increment in symptoms only happens in physical symptoms, although the severity levels are not exacerbated.
\end{abstract}

\section{INTRODUCTION}

As the aging of the world's population becomes more pronounced, valid and reliable measures to assess situationspecific symptoms become an important research direction in order to identify the necessity of interventions, evaluate the impact of therapies and map a specific population on a particular set of problematic occurrences.

Both genders manifest, during the aging process, physical and psychological deterioration with several associated symptoms (including episodic sweating, memory and concentration impairment, anxiety, depressive mood, joint complaints, among others $)^{1}$.

According to the biomedical model, menopause refers to the last menses that occur after a continuous loss of ovarian follicles throughout the reproductive lifespan and gradual reduction of production of hormones by the ovaries, which lead to changes in the length of the menstrual cycle and ultimately to its cessation. This circumscribed occurrence takes place during the menopause transition period ${ }^{2}$. This period encompasses the transition from a reproductive to a non-reproductive life phase, during which the emergence of

Correspondence: Dr F. Pimenta, Psychology and Health Research Unit; ISPA - University Institute of Applied Psychology, Rua Jardim do Tabaco 34, ||49-04| Lisbon, Portugal 
particular symptoms will occur, with their severity being associated with biopsychosocial factors ${ }^{3-5}$. As a result, menopausal symptoms vary greatly across cultures ${ }^{6-8}$.

Usually, women do not experience all menopausal symptoms; it is known that about $75 \%$ of postmenopausal women manifest some symptoms, experiencing them in an acute way. Moreover, different symptoms will have a dissimilar impact, ranging from mild discomfort to extreme distress ${ }^{9}$.

To evaluate these changes that emerge in midlife, several instruments have been designed to assess symptoms that occur during the climacteric period ${ }^{1,10,11}$, including some that were developed from previous scales ${ }^{11}$.

The measurement of menopause symptoms usually includes the evaluation of the presence of the symptoms, but should also include a self-rating assessment of their intensity or severity ${ }^{12}$. However, most of the available measures do not assess simultaneously the frequency and the intensity of each symptom; this would result in a more exact assessment of their severity level.

In order to identify an accurate severity of menopausal symptoms in peri- and postmenopausal women, an inventory, the Menopause Symptoms' Severity Inventory-38 (MSSI-38) was developed to assess the frequency (how many times) and the intensity (how strong/intense) of each symptom. Some of the items included in this inventory are evidenced in the literature as changes that occur during the menopausal transition, but have been absent in previous menopausal scales and checklists. Some examples are the increase in facial hair, weight gain, breast tenderness, loss of head hair, changes in the skin (dryness or texture and tone alterations), as they can be identified as secondary effects of hormone therapy ${ }^{13}$.

\section{METHODS}

\section{Participants}

After having given their informed consent and agreed to participate in the research, a community sample of 992 Portuguese women between 42 and 60 years completed all the instruments adequately (45 women were excluded due to incorrect completion).

The instruments included the MSSI-38, the Portuguese adaptation of the Depression, Anxiety and Stress Scales ${ }^{14}$, the Utian Quality of Life Scale ${ }^{15}$, and the Body Shape Questionnaire ${ }^{16}$, as well as a questionnaire to identify the menopausal status $^{17}$ and to explore sociodemographic, health and menopause-related characteristics. Participants formed a community sample mainly recruited through basic, middle and high schools, universities and corporate settings.

The menopausal status was defined according to Soules and colleagues ${ }^{17}$. Premenopausal women were identified as not having any changes in their menstrual cycle. Perimenopausal women would report variable cycle length (more than 7 days different than usual), or had skipped two or more cycles and had an amenorrhea interval of more than 60 days. Women were confirmed as being postmenopausal if they had at least a 12-month period of amenorrhea.
To improve the accuracy of the determination of menopausal status, in addition to the actual age, the age of the individual when the last menstrual period occurred was also requested. Table 1 describes the characteristics of the pre-, peri- and postmenopausal participants.

\section{The Menopause Symptoms' Severity Inventory-38}

\section{Item generation}

A list of symptoms that could be manifested by peri- and postmenopausal women was compiled from different sources including menopause literature and pre-existing menopauserelated instruments ${ }^{1,10,11}$, the clinical experience of researchers, and the menopause-specific knowledge of three consultants (two gynecologists and one psychologist). Thirty-six semi-structured interviews were also conducted on the subject of menopause experience; these were later reviewed by two researchers to determine, amongst other things, additional symptoms or problematic occurrences.

\section{Question format}

For each symptom, participants were asked how frequent (how many times) and how intense (how strong) the symptom had been during the last month.

Responses were organized on a five-point Likert-type scale (ranging from 0 to 4) for both frequency (that is, 'never', 'yes, less than once a week', 'yes, once or twice a week', 'yes, several times a week', and 'yes, daily or almost every day') and intensity (namely, 'not intense', 'minimum intensity', 'moderate intensity', 'high intensity', or 'extreme intensity').

\section{Item reduction}

After exploratory factor analysis, nine items from the initial 47 were eliminated: strong or fast heartbeat; difficulty in sleeping; mood swings; feeling impatient towards others; flatulence (gas) or pain caused by gas; dry skin; breast tenderness; difficulty in urinating; and very strong and/or irregular vaginal bleeding. These items were excluded because they presented poor association with the factor to which they were predictably associated in the exploratory factor analysis, were absent in at least $50 \%$ of the sample, presented a kurtosis higher than 7 and a skewness higher than 3, or did not have an adequate internal consistency (this was the case of a 13th factor that compiled two items - breast tenderness and strong and/or irregular vaginal bleeding - which had a Cronbach's $\alpha$ of 0.40; composite reliability was also calculated for this factor but again it was very low, 0.51).

The final structure included 38 symptoms, evaluated both in terms of frequency and intensity, and organized in 12 factors (anxiety; depressive mood; cognitive impairment; vasomotor symptoms; numbness; mouth, nails and hair changes; perceived loss of control; sexual symptoms; aches and pain; body shape; skin and facial hair changes; and urinary symptoms). 
Table 1 Distribution of the study's participants according to sociodemographic and health-related characteristics

\begin{tabular}{|c|c|c|c|c|c|c|}
\hline \multirow[b]{2}{*}{ Characteristics } & \multicolumn{2}{|c|}{$\begin{array}{l}\text { Premenopause } \\
\quad(n=282)\end{array}$} & \multicolumn{2}{|c|}{$\begin{array}{c}\text { Perimenopause } \\
\quad(n=298)\end{array}$} & \multicolumn{2}{|c|}{$\begin{array}{l}\text { Postmenopause } \\
(n=412)\end{array}$} \\
\hline & $n$ & $\%$ & $n$ & $\%$ & $n$ & $\%$ \\
\hline Age (years, mean $\pm S D$ ) & $45.7 \pm 3.230$ & & $47.6 \pm 3.787$ & & $53.9 \pm 4.207$ & \\
\hline \multicolumn{7}{|l|}{ Marital status } \\
\hline Married or in a relationship & 202 & 71.9 & 218 & 73.2 & 277 & 67.4 \\
\hline Not married or in a relationship & 79 & 28.1 & 80 & 26.8 & 134 & 32.6 \\
\hline \multicolumn{7}{|l|}{ Education } \\
\hline Primary school & 19 & 6.9 & 28 & 9.5 & 62 & 15.4 \\
\hline Middle school & 51 & 18.5 & 68 & 23.1 & 98 & 24.4 \\
\hline High school & 79 & 28.6 & 91 & 31.0 & 109 & 27.1 \\
\hline University degree & 127 & 46.0 & 107 & 36.4 & 133 & 33.0 \\
\hline \multicolumn{7}{|l|}{ Professional status } \\
\hline Active & 259 & 92.5 & 262 & 89.7 & 317 & 78.7 \\
\hline Inactive & 21 & 7.5 & 30 & 10.3 & 86 & 21.3 \\
\hline \multicolumn{7}{|l|}{ Therapy } \\
\hline Hormone therapy & 4 & 1.5 & 13 & 4.5 & 49 & 13.5 \\
\hline Herbal/soy therapy & 0 & 0 & 16 & 5.5 & 48 & 13.3 \\
\hline Nothing & 273 & 98.5 & 262 & 90.0 & 265 & 73.2 \\
\hline \multicolumn{7}{|l|}{ Body mass index $\left(\mathrm{kg} / \mathrm{m}^{2}\right)$} \\
\hline$\leq 24.9$ & 166 & 59.1 & 157 & 53.0 & 205 & 50.6 \\
\hline$>24.9$ & 115 & 40.9 & 139 & 47.0 & 200 & 49.4 \\
\hline
\end{tabular}

\section{Statistical and psychometric analysis}

To identify whether frequency scores were significantly different from intensity scores, the data distributions of each symptom were compared using the Wilcoxon test for paired samples. Construct validity was asserted by factor analysis (exploratory and confirmatory), convergent and discriminant validity.

To explore the factor structure of the inventory, an exploratory factor analysis was made with PASW Statistics (v. 19.0, SPSS Inc., Chicago, IL, USA), using the principal components method and a varimax rotation. This analysis was made in $60 \%$ of the peri- and postmenopausal sample, randomly selected. To demonstrate the invariance of the measurement model, a confirmatory factor analysis was conducted using AMOS software (v. 18.0, SPSS Inc., Chicago, IL, USA).

The convergent validity of the inventory was analyzed through the average variance extracted (AVE). An adequate value should be higher than $0.50^{18}$. This discriminant validity was explored comparing the squared correlation of interfactors with the AVE of each individual factor. In order to have discriminant validity, the association between factors should be smaller than the individual $\mathrm{AVE}^{18}$.

Criterion validity was explored through concurrentoriented validity of some scales, using Pearson's correlation with similar constructs. To test this, three other subscales were used, namely, the Depression, Anxiety and Stress Scales (DASS $)^{14}$, the Utian Quality of Life Scale for sexual quality of life ${ }^{15}$ and the Body Shape Questionnaire (BSQ) ${ }^{16}$.

In addition, to demonstrate that the measure was adequate in assessing symptoms that occur during menopause (that is, during the menopausal transition and postmenopause), the invariance of the measurement model was tested by integrating, in the analysis, women who were not in the menopause phase (premenopausal participants), and therefore were not expected to have menopausal symptoms. This analysis had the purpose of proving that the measurement model would be variant when using a group of women who were not in menopause.

Reliability was studied applying the Cronbach's $\alpha$, and sensitivity was explored through the analysis of minimum and maximum values, skewness and kurtosis. Values are expected to range from 0 to 4 and skewness and kurtosis are expected to have values below 3 and 7 respectively, while reliability scores should be above $0.70^{18}$.

To evaluate whether age could function as a moderator for the impact of menopausal status over the symptoms, a structural model was built to evaluate a possible interaction effect with the 12 symptoms.

Finally, to explore whether there are significant differences between women in peri- and postmenopause, regarding the 12 sets of symptoms, a one-way ANOVA was applied. 
Table 2 Mean (standard deviation) of each symptom in terms of frequency and intensity (for the sample of peri- and postmenopausal women) and comparison of these two ways of assessment (Wilcoxon test)

\begin{tabular}{|c|c|c|c|}
\hline Items & Frequency & Intensity & $\begin{array}{c}\text { Wilcoxon test } \\
\text { (freq.- vs. int.) } \\
\text { Z sig. }{ }^{\dagger}\end{array}$ \\
\hline 1. Feeling tense or nervous & $1.59(1.065)$ & $1.49(1.000)$ & $-3.825 * * *$ \\
\hline 2. Getting easily excited (i.e. agitated, excited or startled) & $1.30(1.170)$ & $1.21(1.094)$ & $-3.900 * * *$ \\
\hline 3. Panic attacks & $0.27(0.720)$ & $0.29(0.726)$ & -1.278, n.s. \\
\hline 4. Difficulty in concentrating & $1.27(1.144)$ & $1.19(1.056)$ & $-3.277 * * *$ \\
\hline 5. Feeling tired or with lack of energy & $1.78(1.215)$ & $1.59(1.101)$ & $-6.792 * * *$ \\
\hline 6. Loss of interest in most things & $0.87(1.100)$ & $0.84(1.076)$ & -1.363 , n.s. \\
\hline 7. Crying spells & $0.63(1.015)$ & $0.63(0.990)$ & -0.175 , n.s. \\
\hline 8. Irritability & $1.31(1.051)$ & $1.28(1.059)$ & -1.228 , n.s. \\
\hline 9. Being unhappy with personal life & $1.09(1.157)$ & $1.01(1.113)$ & $-3.119 * *$ \\
\hline 10. Feeling anxious or nervous & $1.50(1.099)$ & $1.36(1.042)$ & $-5.568 * * *$ \\
\hline 11. Feeling a loss or lack of memory & $1.39(1.194)$ & $1.22(1.094)$ & $-6.407 * * *$ \\
\hline 12. Overall decrease in performance capacity (e.g. doing less things than you are used to do) & $1.27(1.177)$ & $1.15(1.089)$ & $-5.058 * *$ \\
\hline 13. Feeling depressed, down or sad & $1.27(1.165)$ & $1.21(1.096)$ & $-2.142 *$ \\
\hline 14. Wanting to be alone & $1.37(1.273)$ & $1.28(1.224)$ & $-3.821 * * *$ \\
\hline 15. Feeling dizzy or fainting & $0.44(0.815)$ & $0.42(0.822)$ & -1.426 , n.s. \\
\hline 16. Sense of tension and pressure in head or body & $1.10(1.103)$ & $1.02(1.042)$ & $-3.564 * * *$ \\
\hline 17. Numbness or tingling in some body parts & $1.21(1.271)$ & $1.09(1.167)$ & $-5.112 * *$ \\
\hline 18. Headache & $1.22(1.143)$ & $1.22(1.130)$ & -0.212 , n.s. \\
\hline 19. Pain in the muscles and joints & $1.69(1.297)$ & $1.53(1.203)$ & $-5.757 * * *$ \\
\hline 20. Loss of sensation in hands or feet & $0.74(1.137)$ & $0.67(1.050)$ & $-2.683 * *$ \\
\hline 21. Difficulty in breathing or breathlessness & $0.56(0.989)$ & $0.51(0.896)$ & $-2.812 * *$ \\
\hline 22. Pain in the back of neck or head & $1.53(1.306)$ & $1.42(1.185)$ & $-4.581 * * *$ \\
\hline 23. Decrease in physical strength & $1.32(1.210)$ & $1.20(1.099)$ & $-4.447 * * *$ \\
\hline 24. Weight gain & $1.06(1.223)$ & $1.00(1.174)$ & $-2.387^{*}$ \\
\hline 25. Increased facial hair & $0.62(1.029)$ & $0.56(0.956)$ & $-3.295 * *$ \\
\hline 26. Changes in appearance, texture or tone of skin & $0.67(1.003)$ & $0.62(0.951)$ & $-2.969 * *$ \\
\hline 27. Feeling bloated & $1.39(1.239)$ & $1.27(1.190)$ & $-4.654 * * \%$ \\
\hline 28. Lower back pain & $1.82(1.330)$ & $1.68(1.235)$ & $-4.719 * * *$ \\
\hline 29. Urine loss when laughing or coughing & $0.98(1.254)$ & $0.82(1.108)$ & $-6.302 * * *$ \\
\hline 30. Hot flushes & $1.17(1.411)$ & $1.06(1.296)$ & $-4.831 * * *$ \\
\hline 31. Night sweats & $1.15(1.383)$ & $1.03(1.276)$ & $-5.663 * * *$ \\
\hline 32. Excessive sweating & $0.74(1.123)$ & $0.71(1.081)$ & $-1.959 *$ \\
\hline 33. Loss of sexual interest & $1.50(1.364)$ & $1.41(1.287)$ & $-3.868 * * *$ \\
\hline 34. Excessive wish to urinate & $0.77(1.124)$ & $0.67(1.033)$ & $-4.594 * * *$ \\
\hline 35. Vaginal dryness (feeling of dryness, burning and problems during sexual intercourse) & $1.03(1.269)$ & $0.97(1.206)$ & $-3.279 * *$ \\
\hline 36. Hair problems (e.g. insufficient or excessive hair) & $0.73(1.101)$ & $0.71(1.042)$ & -1.583 , n.s. \\
\hline 37. Nail changes (changes in color, thickness, appearance of nail, etc.) & $0.72(1.119)$ & $0.70(1.081)$ & -1.781 , n.s. \\
\hline $\begin{array}{l}\text { 38. Mouth and teeth problems (pain and burning feeling in the gums, altered taste, } \\
\text { increased sensitivity to hot and cold, dry mouth, etc.) }\end{array}$ & $0.80(1.092)$ & $0.75(1.054)$ & $-2.204 *$ \\
\hline
\end{tabular}

${ }^{\dagger}$, two-tailed; n.s. not significant; $*, p \leq 0.05 ; * *, p \leq 0.01 ; * *, p \leq 0.001$; freq. vs. int., frequency vs. intensity

\section{RESULTS}

\section{Frequency and intensity}

To confirm whether the frequency was significantly different from the intensity measurement, the frequency and intensity of every item (or symptom) were compared with the Wilcoxon test for paired samples. As evidenced in Table 2, there are significant differences between the measurement of frequency and intensity, for most symptoms.

To analyze the psychometric qualities of the measures assessed by the inventory, construct-related and criterion validity were evaluated for each factor. Moreover, reliability, sensitivity and measurement invariance, in two independent samples, were also explored. The severity of each symptom is given by the mean of the frequency and intensity for that symptom. 


\section{Construct validity}

\section{Factorial validity}

The exploratory factor analysis was performed, using PASW Statistics (v. 19.0), on $60 \%$ of the randomly selected data, from the total sample of peri- and postmenopausal women. Factors extracted were those with an eigenvalue greater than 1 and theory-supported. The best-fit solution was a 12 -factor structure, excluding nine items from the original inventory. The sampling adequacy was confirmed by the Kaiser-MeyerOlkin test $(\mathrm{KMO}=0.938)$ and the total variance explained by this 12 -factor structure is $73.0 \%$. Table 3 presents the range of loadings of all symptoms that compose each one of the 12 factors.

\section{Convergent validity}

All subscales present good AVE scores (i.e. $\geq 0.50$ ) except for the mouth, nails and hair changes (0.41) and perceived loss of control (0.38) subscales.

\section{Discriminant validity}

Of the possible comparisons for the 66 paired-factors, for the existent 12 factors, 57 presented good discriminant validity. The nine exceptions with low discriminant validity were the following pairs: depressive mood and cognitive impairment; cognitive impairment and aches/pain; depressive mood and anxiety; aches/pain and numbness; skin, facial hair changes and body shape; depressive mood and perceived loss of control; aches/pain and perceived loss of control; mouth, nails and hair changes and perceived loss of control; and anxiety and perceived loss of control.

\section{Criterion validity}

MSSI-38's anxiety subscale was highly related with DASS's anxiety factor $\left(r_{p}=0.617 ; p<0.001\right)$. In addition, MSSI-38's depressive mood was also strongly associated with DASS's depression subscale $\left(r_{p}=0.736 ; p<0.001\right)$. The association between sexual quality of life and sexual symptoms was both negative and significant $\left(r_{p}=-0.221 ; p<0.001\right)$, as expected. Finally, MSSI-38's body shape was also correlated with the total of BSQ $\left(r_{p}=0.557 ; p<0.001\right)$.

\section{Multi-group analysis}

\section{Invariance analysis}

The model presents a good adjustment $\left(\chi^{2} /\right.$ d.f. $=2.055$; comparative fit index $(\mathrm{CFI})=0.895$; goodness-of-fit index $(\mathrm{GFI})=0.830$; root mean square error of approximation $(\mathrm{RMSEA})=0.039, p=1.000,90 \%$ confidence interval $(\mathrm{CI})$
Table 3 Range of the symptoms loadings for each factor

\begin{tabular}{|c|c|c|c|}
\hline Factors & $\begin{array}{l}\text { Number } \\
\text { of items }\end{array}$ & $\begin{array}{c}\text { Range of } \\
\text { symptoms } \\
\text { loadings }\end{array}$ & $\begin{array}{c}\text { Variance } \\
\text { explained } \\
\text { by factor } \\
(\%)\end{array}$ \\
\hline Anxiety & 5 & $0.495-0.754$ & 9.407 \\
\hline Depressive mood & 5 & $0.643-0.743$ & 9.112 \\
\hline Aches and pain & 6 & $0.478-0.754$ & 8.769 \\
\hline Cognitive impairment & 3 & $0.619-0.726$ & 7.247 \\
\hline Vasomotor symptoms & 3 & $0.705-0.899$ & 6.555 \\
\hline Mouth, nails and hair changes & 3 & $0.577-0.785$ & 5.502 \\
\hline Perceived loss of control & 3 & $0.586-0.680$ & 4.859 \\
\hline Numbness & 2 & $0.762-0.767$ & 4.763 \\
\hline Urinary symptoms & 2 & $0.748-0.783$ & 4.462 \\
\hline Sexual symptoms & 2 & $0.705-0.823$ & 4.302 \\
\hline Skin and facial hair changes & 2 & $0.670-0.800$ & 4.065 \\
\hline Body shape & 2 & $0.677-0.688$ & 3.963 \\
\hline Total variance explained (\%) & 38 & & 73.006 \\
\hline
\end{tabular}

$0.037-0.041)$ in both groups $(60 \%$ and $40 \%$ of the sample of peri- and postmenopausal women).

The unconstrained measurement model does not have a significantly better fit than the model with constrained factorial weights $\left(\chi^{2}(26)=27.229 ; p=0.397\right)$, hence confirming the invariance of the measurement model. Therefore, there are no significant differences in the factorial measurement weights between both groups ( $60 \%$ of the sample vs. $40 \%$ ), confirming the assessment's stability of the 12 constructs comprised in the MSSI-38.

\section{Pre-vs. peri-vs. postmenopausal participants}

This measure also presented a good adjustment to the global sample, that is, 992 women in pre-, peri- and postmenopause $\left(\chi^{2} /\right.$ d.f. $=3.415 ; \mathrm{CFI}=0.923 ; \mathrm{GFI}=0.901 ; \mathrm{RMSEA}=0.049$, $p=0.735 ; 90 \%$ CI $0.047-0.051)$. As expected, when women in premenopause are included, the measurement weights are significantly different $\left(\chi^{2}(52)=82.208 ; p=0.005\right)$, supporting the variance of the measure in the groups. However, and again as expected, if only peri- and postmenopausal women are considered, the constrained measurement model does not have a significantly better adjustment than the unconstrained one $\left(\chi^{2}(26)=30.448 ; p=0.249\right)$. These results support the inventory's stability as a measure for menopausal symptoms that are observed in peri- and postmenopausal women $\left(\chi^{2} /\right.$ $\mathrm{df}=2.131 ; \quad \mathrm{CFI}=0.888 ; \quad \mathrm{GFI}=0.827 ; \quad \mathrm{RMSEA}=0.040$, $p=1.000 ; 90 \%$ CI $0.038-0.042)$.

\section{Reliability}

The internal consistency of these 12 subscales was also explored. All subscales presented an acceptable Cronbach's $\alpha$, as shown in Table 4. 
Table 4 Internal consistency of the 12 subscales

\begin{tabular}{lcc}
\hline Subscales & Number of items & $\begin{array}{c}\text { Cronbach's } \alpha \\
\text { for severity }\end{array}$ \\
\hline Anxiety & 5 & 0.899 \\
Depressive mood & 5 & 0.870 \\
Aches and pain & 6 & 0.859 \\
Cognitive impairment & 3 & 0.815 \\
Vasomotor symptoms & 3 & 0.847 \\
Mouth, nails and hair changes & 3 & 0.701 \\
Perceived loss of control & 3 & 0.674 \\
Numbness & 2 & 0.793 \\
Urinary symptoms & 2 & 0.653 \\
Sexual symptoms & 2 & 0.716 \\
Skin and facial hair changes & 2 & 0.613 \\
Body shape & 2 & 0.737
\end{tabular}

\section{Sensitivity}

To address sensitivity, the range of the Likert-type scale was explored as well as the skewness and kurtosis values for the severity of all symptoms, as shown in Table 5 .

In addition, to evaluate the sensitivity of the subscales, minimum and maximum values, as well as skewness and kurtosis, were explored for the severity of the 12 sets of symptoms, as shown in Table 6.

\section{Symptom severity in peri- vs. postmenopausal participants}

A structural model was built to explore whether age was a confounding variable. The results showed that there is a negative and significant interaction in two sets of symptoms. This means that, for both skin and facial hair changes $(\beta=-0.183$; $p=0.028)$ and vasomotor symptoms $(\beta=-0.228 ; p=0.001)$, age moderates the effect of menopausal status over these two sets of symptoms.

The mean severity was calculated for each subscale, for periand postmenopausal participants separately, and a Student $t$-test was used to analyze whether both groups diverged significantly in the 12 groups of symptoms, as observed in Table 7.

\section{DISCUSSION}

Patient-reported outcomes are useful not only in the context of research but also in clinical settings, as they allow the identification of psychological and physical symptoms that might be unobserved, and permit the monitoring of the evolution of symptoms and exploration of pertinent information regarding the implemented treatment ${ }^{19}$. Specifically for menopause, the literature evidences the importance of the availability of indexes that cover both menopausal symptoms and the potential side-effects of hormone therapy ${ }^{20}$.
Some of the nine excluded items have received some attention in the menopause literature. Specifically, difficulty in sleeping has been associated with vasomotor symptoms and psychosocial factors ${ }^{21,22}$. This was not found in the present research, given that this particular item was never associated with the vasomotor symptom scale. The low severity of vasomotor symptoms in this community sample might partially explain the absence of this association.

Dysuria (difficulty in urinating) was also excluded, although there was clearly a factor compiling urinary symptoms (which was kept due to its good psychometric characteristics and theoretical sustainability) with which this item was never related. This may evidence that dysuria is not an observed urinary symptom in this sample of peri- and postmenopausal women.

The poor discriminant validity between some subscales, namely between perceived loss of control and depressive mood, anxiety, aches and pain, mouth, nails and hair changes, might evidence that some psychological and physical symptoms may enhance the perception of decreased control.

Breast tenderness and very strong and/or irregular vaginal bleeding, although being related to hormonal changes ${ }^{23}$ and the side-effects of hormone therapy ${ }^{24}$, and therefore important items to include in a menopausal symptoms scale, showed, in this study, a very low internal consistency. As a result, this factor was not included in the final version of the inventory.

The MSSI-38 provided data with good psychometric properties. Thus, the MSSI-38 may be used to accurately measure the severity of menopause symptoms, considering both the frequency and intensity of each symptom. The inclusion of these two evaluation elements is important, given that the times a symptom occurs (frequency) and the intensity (how intense/strong) of the symptom are two significantly different ways of evaluating it, as shown above. As analyzed, 30 of the 38 symptoms presented statistically significant differences between their frequency and intensity measurements.

In addition, it was also shown that the frequency assessment of the symptoms presents higher means when compared with intensity: except for item 3, 'panic attacks' (where frequency is lower than intensity) and items 7 , 'crying spells', and 18, 'headache' (which present an equal mean frequency and intensity), all symptoms are more frequent than intense. Hence, studies considering only intensity may obtain lower levels of reported symptoms than those assessing the frequency of each symptom. This conclusion is supported by a prior study ${ }^{25}$ regarding the vasomotor symptoms: although $57 \%$ of women in their study reported hot flushes, only $9 \%$ considered these to be bothersome. Likewise, night sweats were manifested by $36 \%$ of participants; however, only $6 \%$ considered them to be troublesome.

The MSSI-38 allows the measurement of 12 types of symptoms, of both physical and psychological nature. Thus, it allows the calculation of 12 distinct indexes of symptom severity, corresponding to the 12 subscales of this instrument.

Results show that the mean severity of symptoms is low (ranging from 0.4 to 1.4 in a scale from 0 to 4 ) in both peri- and postmenopausal women. This supports the idea that the great majority of women in this community sample do not present a high severity of menopausal symptoms. This is congruent with 
Table 5 Minimum and maximum values, skewness and kurtosis for the 38 items

\begin{tabular}{|c|c|c|c|c|}
\hline Item & Minimum & Maximum & Skewness & Kurtosis \\
\hline 1. Feeling tense or nervous & 0 & 4 & 0.326 & -0.497 \\
\hline 2. Getting easily excited (i.e. agitated, excited or startled) & 0 & 4 & 0.599 & -0.572 \\
\hline 3. Panic attacks & 0 & 4 & 2.902 & 8.236 \\
\hline 4. Difficulty in concentrating & 0 & 4 & 0.696 & -0.224 \\
\hline 5. Feeling tired or with lack of energy & 0 & 4 & 0.324 & -0.762 \\
\hline 6. Loss of interest in most things & 0 & 4 & 1.249 & 0.620 \\
\hline 7. Crying spells & 0 & 4 & 1.686 & 2.092 \\
\hline 8. Irritability & 0 & 4 & 0.625 & -0.165 \\
\hline 9. Being unhappy with personal life & 0 & 4 & 0.976 & 0.009 \\
\hline 10. Feeling anxious or nervous & 0 & 4 & 0.448 & -0.472 \\
\hline 11. Feeling a loss or lack of memory & 0 & 4 & 0.575 & -0.594 \\
\hline $\begin{array}{l}\text { 12. Overall decrease in performance capacity (e.g. doing less things than you are } \\
\text { used to do) }\end{array}$ & 0 & 4 & 0.732 & -0.368 \\
\hline 13. Feeling depressed, down or sad & 0 & 4 & 0.696 & -0.350 \\
\hline 14. Wanting to be alone & 0 & 4 & 0.711 & -0.597 \\
\hline 15. Feeling dizzy or fainting & 0 & 4 & 2.194 & 4.703 \\
\hline 16. Sense of tension and pressure in head or body & 0 & 4 & 0.849 & -0.160 \\
\hline 17. Numbness or tingling in some body parts & 0 & 4 & 0.844 & -0.409 \\
\hline 18. Headache & 0 & 4 & 0.735 & -0.282 \\
\hline 19. Pain in the muscles and joints & 0 & 4 & 0.338 & -0.961 \\
\hline 20. Loss of sensation in hands or feet & 0 & 4 & 1.464 & 1.050 \\
\hline 21. Difficulty in breathing or breathlessness & 0 & 4 & 1.836 & 2.643 \\
\hline 22. Pain in the back of neck or head & 0 & 4 & 0.455 & -0.882 \\
\hline 23. Decrease in physical strength & 0 & 4 & 0.640 & -0.580 \\
\hline 24. Weight gain & 0 & 4 & 1.066 & 0.122 \\
\hline 25. Increased facial hair & 0 & 4 & 1.862 & 2.844 \\
\hline 26. Changes in the appearance, texture or tone of skin & 0 & 4 & 1.713 & 2.402 \\
\hline 27. Feeling bloated & 0 & 4 & 0.581 & -0.772 \\
\hline 28. Lower back pain & 0 & 4 & 0.189 & -1.054 \\
\hline 29. Urine loss when laughing or coughing & 0 & 4 & 1.257 & 0.509 \\
\hline 30. Hot flushes & 0 & 4 & 0.955 & -0.453 \\
\hline 31. Night sweats & 0 & 4 & 1.004 & -0.338 \\
\hline 32. Excessive sweating & 0 & 4 & 1.573 & 1.516 \\
\hline 33. Loss of sexual interest & 0 & 4 & 0.580 & -0.893 \\
\hline 34. Excessive wish to urinate & 0 & 4 & 1.610 & 1.782 \\
\hline $\begin{array}{l}\text { 35. Vaginal dryness (feeling of dryness, burning and problems during sexual } \\
\text { intercourse) }\end{array}$ & 0 & 4 & 1.085 & -0.034 \\
\hline 36. Hair problems (e.g. insufficient or excessive hair) & 0 & 4 & 1.580 & 1.640 \\
\hline 37. Nail changes (changes in color, thickness, appearance of nail, etc.). & 0 & 4 & 1.693 & 1.932 \\
\hline $\begin{array}{l}\text { 38. Mouth and teeth problems (pain and burning feeling in the gums, altered taste, } \\
\text { increased sensitivity to hot and cold, dry mouth, etc.). }\end{array}$ & 0 & 4 & 1.475 & 1.430 \\
\hline
\end{tabular}

a previous study ${ }^{26}$ which concluded that, although menopausal symptoms are common in middle-aged women, they are usually not perceived as problematic. Also, it has been concluded that a higher educational level is associated with less complaints of symptoms ${ }^{21,27}$; given that a large number of participants had a university degree (specifically, 37\% of the total sample), this might also explain the low severity of menopausal symptoms reported. However, there is also the possibility that the self-report methodology has resulted in an under-report of the symptoms; as examined elsewhere ${ }^{28}$, highly symptomatic participants under-reported the number of objective (physiological) hot flushes by $43 \%$.
Nevertheless, the low severity of symptoms might be due to the fact that this is a community and not a clinical sample. The use of a community sample in this study aimed to overcome a limitation that is usually seen in menopausal research which is the fact that many studies use clinical samples, thus excluding the extrapolation to a non-clinical population ${ }^{29}$.

Moreover, most women in this research were not taking hormonal therapy or herbal/soy products to decrease menopausal symptoms $(90 \%$ and $73.2 \%$ of peri- and postmenopausal women, respectively, did not take any medicine or supplement to manage menopausal symptoms); thus, the probability of the symptoms being under-reported due to medication is 
Table 6 Minimum and maximum values, skewness and kurtosis for the 12 subscales

\begin{tabular}{lcccr}
\hline Subscales & Minimum & Maximum & Skewness & Kurtosis \\
\hline Anxiety & 0 & 4 & 0.490 & -0.315 \\
$\begin{array}{l}\text { Depressive mood } \\
\text { Aches and pain }\end{array}$ & 0 & 4 & 1.050 & 0.487 \\
$\quad \begin{array}{l}\text { Cognitive } \\
\quad \text { impairment }\end{array}$ & 0 & 4 & 0.571 & -0.258 \\
$\quad$ Vasomotor & 0 & 4 & 1.134 & 0.278 \\
$\quad$ symptoms & & & & \\
$\begin{array}{l}\text { Mouth, nails and } \\
\quad \text { hair changes }\end{array}$ & 0 & 4 & 1.616 & 2.449 \\
$\quad \begin{array}{l}\text { Perceived loss of } \\
\quad \text { control }\end{array}$ & 0 & 4 & 2.135 & 5.073 \\
$\quad \begin{array}{l}\text { Numbness } \\
\text { Urinary symptoms }\end{array}$ & 0 & 4 & 1.134 & 0.421 \\
$\begin{array}{l}\text { Sexual symptoms } \\
\quad \text { Skin and facial hair }\end{array}$ & 0 & 4 & 1.502 & 1.851 \\
$\quad$ changes & 0 & 4 & 1.698 & 2.807 \\
$\quad$ Body shape & 0 & 4 & 0.836 & -0.094 \\
\hline
\end{tabular}

diminished. However, the possibility that the subgroup of women taking hormone therapy (or herbal/soy therapy) may have reported lower levels of symptoms than they would have if therapy was not being used, cannot be discarded.

An increase in symptom reporting is usually expected during the progression through the menopausal stages ${ }^{27}$. Melby, Lock and Kaufert ${ }^{30}$ showed that, although symptom reporting during premenopause is consistently lower, when compared with peri- and postmenopause phases, it is still not unanimous in which one of the two latter menopausal stages (peri- or postmenopause) higher rates of symptoms are reported. Regarding hot flushes, their prevalence has been evidenced as higher in post- than in perimenopausal women: $37 \%$ of pre-, $48 \%$ of early peri-, $63 \%$ of late peri- and $79 \%$ of postmenopausal women have reported these vasomotor symptoms in previous research ${ }^{31}$. Guthrie and colleagues ${ }^{32}$ have also concluded that the presence of higher rates of bothersome hot flushes is observed 2 years after the final menstrual period. However, this conclusion it is not unanimous, since some authors have verified a decrease in menopausal symptoms from peri- to postmenopause ${ }^{33}$, or found perimenopausal women more prone than their counterparts in pre- and postmenopause to experience aches and pains (head, back or joint); however, vasomotor symptoms were more prevalent in postmenopause, remaining high in this stage ${ }^{34}$.

In this research, although no analysis was made in terms of comparing early with late perimenopause; the differences between women in menopausal transition (perimenopause) and postmenopause are not significant in all symptoms. The symptoms that increase significantly are eminently physical (aches and pains, vasomotor symptoms, numbness, skin and facial hair changes, urinary and sexual symptoms). Psychological symptoms such as depressive mood, anxiety and perceived loss of control, do not increase significantly from menopausal transition to postmenopause. This conclusion is congruent with a previous study which found that postmenopausal women do not present a higher prevalence of psychological symptoms, reporting only more hot flushes and night sweats ${ }^{4}$.

The same research, when comparing women in pre- and postmenopause, did not find significant differences in the occurrence of the vast majority of symptoms (anxiety, depression, somatic and sexual symptoms did not diverge between the two groups $)^{4}$. However, the present research evidences that, when comparing women in premenopause with participants in menopausal transition and postmenopause, differences in symptom measurements are observed, indicating different measurement weights according to the menopausal status.

Memory functioning has also been observed to be decreased in perimenopausal women when compared with their postmenopausal counterparts ${ }^{35}$. This was not observed in the present sample given that there are no significant differences in cognitive impairment (which encompasses a memory selfreported assessment) between peri- and postmenopausal women.

Table 7 Mean (standard deviation) severity scores and Student $t$-value for peri- and postmenopause comparison

\begin{tabular}{|c|c|c|c|}
\hline Symptoms & Perimenopause & Postmenopause & T-test $t$ (d.f.) sig $^{\dagger}$ \\
\hline Depressive mood & $1.0(0.909)$ & $1.0(0.952)$ & -1.029 (676), n.s. \\
\hline Cognitive impairment & $1.1(0.952)$ & $1.2(0.962)$ & -1.352 (674), n.s. \\
\hline Aches and pain & $1.2(0.873)$ & $1.4(0.934)$ & $-2.395(684)^{*}$ \\
\hline Vasomotor symptoms & $0.7(0.979)$ & $1.1(1.186)$ & $-4.456(660.440)^{* * *}$ \\
\hline Numbness & $0.8(1.012)$ & $1.0(1.058)$ & $-2.003(665) *$ \\
\hline Mouth, nails and hair changes & $0.6(0.846)$ & $0.7(0.833)$ & $-0.946(655)$, n.s. \\
\hline Anxiety & $1.4(0.895)$ & $1.4(0.926)$ & -0.287 (683), n.s. \\
\hline Skin and facial hair changes & $0.5(0.758)$ & $0.7(0.830)$ & $-3.433(627.359) * * *$ \\
\hline Urinary symptoms & $0.6(0.876)$ & $0.9(1.021)$ & $-3.133(648.911)^{* * *}$ \\
\hline Sexual symptoms & $0.9(1.018)$ & $1.4(1.208)$ & $-5.634(649.321) * * *$ \\
\hline Body shape & $1.1(1.042)$ & $1.1(1.094)$ & -0.195 (667), n.s. \\
\hline Perceived loss of control & $0.4(0.624)$ & $0.5(0.695)$ & -1.697 (642.851), n.s. \\
\hline
\end{tabular}

${ }^{\dagger}$, Two-tailed; n.s., not significant; *, $p \leq 0.05 ; * *, p \leq 0.01 ; * *, p \leq 0.001$ 
The results also show that age moderates the effect of menopausal status over two types of symptoms (vasomotor and skin and facial hair changes). Since the interaction is negative, the impact of menopausal status on the symptoms is suppressed by age. Therefore, as age progresses, vasomotor symptoms and changes in skin and facial hair are influenced less by menopausal status. Similar conclusions have been mentioned in the literature, namely, that somatic symptoms of menopause are negatively and significantly related with age progression ${ }^{36}$ and also that skin changes are observed in the aging process ${ }^{37}$.

Although the MSSI-38 was applied to women from 42 to 60 years old, it is believed that this instrument will also be useful in assessing postmenopausal symptoms in women older than 60. Further research with this age group and other ethnicities and cultures is recommended, since this is a mostly Caucasian Portuguese sample.

In conclusion, the Menopausal Symptom Severity Inventory-38 is an instrument with good psychometric properties that assesses menopausal symptoms, both in frequency and intensity, in order to obtain an accurate degree of symptom severity. This inventory has been proven to have factorial, convergent and discriminant validity. Moreover, criterion validity for some scales as well as a good reliability and sensitivity for all scales has been shown. More studies are needed to confirm this structure with other samples (for example, clinical ones, given that this inventory was generated in a community sample) and cultures (since there is evidence that cultural and ethnical differences may influence the menopause experience).

\section{ACKNOWLEDGEMENTS}

We thank Raquel Oliveira for proofreading the manuscript. We thank Professor Jorge Branco and his colleagues for their expert contribution in the revision of the inventory.

Conflict of interest The authors report no conflicts of interest. The authors alone are responsible for the content and writing of the paper.

Source of funding We kindly acknowledge the Portuguese Foundation for Science and Technology (FCT), for the grant SFRH/BD/32359/2006 which allowed this research.

\section{References}

1. Heinemann K, Ruebig A, Potthoff P, et al. The Menopause Rating Scale (MRS): a methodological review. Health Qual Life Outcome 2004;2:45-52

2. Speroff L, Fritz MA. Clinical Gynaecology, Endocrinology and Infertility. Philadelphia: Lippincott Williams \& Wilkins, 2005:621-88

3. Binfa L, Castelo-Branco C, Blümel JE, et al. Influence of psychosocial factors on climacteric symptoms. Maturitas 2004;48: 425-31

4. Blümel JEM, Castelo-Branco C, Cancelo MJ, et al. Relation between psychological complaints and vasomotor symptoms during climacteric. Maturitas 2004;49:205-10

5. Sierra B, Hidalgo LA, Chedraui PA. Measuring climacteric symptoms in an Ecuadorian population with the Greene Climacteric Scale. Maturitas 2005;51:236-45

6. Dennerstein L. Well-being, symptoms and the menopausal transition. Maturitas 1996;23:147-57

7. Fu SY, Anderson D, Courtney M. Cross-cultural menopausal experience: comparison of Australian and Taiwanese women. Nurs Health Sci 2003;5:77-84

8. Haines CJ, Xing SM, Park KH, Holinka CF, Ausmanas MK. Prevalence of menopausal symptoms in different ethnic groups of Asian women and responsiveness to therapy with three doses of conjugated estrogens/medroxyprogesterone acetate: The Pan-Asia Menopause (PAM) study. Maturitas 2005;52:264-76

9. Samsioe G, Doren M, Lobo RA. Acute symptoms of the menopause. Womens Health Med 2006;3:282-6

10. Greene JC. Constructing a standard climacteric scale. Maturitas 1998;29:25-31

11. Hilditch JR, Lewis J, Peter A, et al. A menopause-specific quality of life questionnaire: development and psychometric properties. Maturitas 1996;24:161-75
12. Berg JA, Larson CA, Pasvogel AE. Menopausal symptoms perception and severity: results from a screening questionnaire. J Clin Nurs 2008;17:940-8

13. Munarriz R, Talakoub L, Flaherty E, et al. Androgen replacement therapy with dehydroepiandrosterone for androgen insufficiency and female sexual dysfunction: Androgen and questionnaire results. J Sex Marital Ther 2002;28:165-73

14. Lovibond PF, Lovibond SH. The structure of negative emotional states: comparison of the Depression Anxiety Stress Scales (DASS) with the Beck Depression and Anxiety Inventories. Behav Res Ther 1995;33:335-43

15. Utian WH, Janata JW, Kingsberg SA, Schluchter M, Hamilton JC. The Utian Quality of Life (UQOL) Scale: development and validation of an instrument to quantify quality of life through and beyond menopause. Menopause 2002;9:402-10

16. Cooper PJ, Taylor MJ, Cooper Z, Fairburn CG. The development and validation of the body shape questionnaire. Int J Eat Disord 1987;6:485-94

17. Soules MR, Sherman S, Parrott E, et al. Stages of Reproductive Aging Workshop. J Womens Health Gend Based Med 2001; 10:843-8

18. Maroco J. Análise de Equações Estruturais. Pero Pinheiro, Report Number, 2010

19. Valderas JM, Kotzeva A, Espallargues M, et al. The impact of measuring patient-reported outcomes in clinical practice: a systematic review of the literature. Qual Life Res 2008;17:179-93

20. Brazier JE, Roberts J, Platts M, Zoellner YF. Estimating a preference-based index for a menopause specific health quality of life questionnaire. Health Qual Life Outcome 2005;3:13-19

21. Dennerstein L, Dudley EC, Hopper JL, Guthrie JR, Burger HG. A prospective population-based study of menopausal symptoms. Obstet Gynecol 2000;96:351-8 
22. Ohayon MM. Severe hot flashes are associated with chronic insomnia. Arch Intern Med 2006;166:1262-8

23. Guthrie JR, Dennerstein L, Taffe JR, Lehert P, Burger HG. The menopausal transition: a 9-year prospective population-based study. The Melbourne Women's Midlife Health Project. Climacteric 2004;7:375-89

24. Tosteson ANA, Gabriel SE, Kneeland TS, et al. Has the impact of hormone replacement therapy on health-related quality of life been undervalued? J Womens Health Gend Based Med 2000;9: 119-30

25. Sievert LL, Obermeyer CM, Price K. Determinants of hot flashes and night sweats. Ann Hum Biol 2006;33:4-16

26. Porter M, Penney GC, Russell D, Russell E, Templeton A. A population based survey of women's experience of the menopause. Br J Obstet Gynaecol 1996;103:1025-8

27. Chedraui P, Aguirre W, Hidalgo L, Fayad L. Assessing menopausal symptoms among healthy middle aged women with the Menopause Rating Scale. Maturitas 2007;57:271-8

28. Maki PM, Drogos LL, Rubin LH, Banuvar S, Shulman LP, Geller SE. Objective hot flashes are negatively related to verbal memory performance in midlife women. Menopause 2008;15:848-56

29. Collins A, Landgren BM. Longitudinal research on the menopause-methodological challenges. Acta Obstet Gynecol Scand 2002;81:579-80
30. Melby MK, Lock M, Kaufert P. Culture and symptom reporting at menopause. Hum Reprod Update 2005;11:495-512

31. Freeman E, Sammel M, Lin H, Gracia C, Kapoor S, Ferdousi T. The role of anxiety and hormonal changes in menopausal hot flashes. Menopause 2005;12:258-66

32. Guthrie JR, Dennerstein L, Taffe JR, Donnelly V. Health care-seeking for menopausal problems. Climacteric 2003;6: 112-17

33. Blümel JE, Roncagliolo ME, Gramegna GM, Tacla X, Sepúlveda $\mathrm{H}$, Brandt A. Prevalencia de síntomas psíquicos y vasomotores en diferentes periodos del climaterio. Rev Child Obstet Ginecol 1997;62:412-18

34. Brown WJ, Mishra GD, Dobson A. Changes in physical symptoms during the menopause transition. Int J Behav Med 2002;9: 53-67

35. Woods NF, Mitchell ES. Memory Functioning Among Midlife Women: Observations from the Seattle Midlife Women's Health Study. Menopause 2000;7:257-65

36. Hunter M. Somatic experience of menopause: a prospective study. Psychosomatic Medicine 1990;52:357-67

37. Sumino H, Ichikawa S, Abe M, Endo Y, Ishikawa O, Kurabayashi M. Effects of aging, menopause, and hormone replacement therapy on forearm skin elasticity in women. J Am Geriatr Soc 2004;52:945-9 